\title{
Pontine Nitric Oxide Modulates Acetylcholine Release, Rapid Eye Movement Sleep Generation, and Respiratory Rate
}

\author{
Timothy O. Leonard and Ralph Lydic \\ Department of Anesthesia and the Program in Neuroscience, The Pennsylvania State University College of Medicine, \\ Hershey, Pennsylvania 17033
}

\begin{abstract}
Pontine cholinergic neurotransmission is known to play a key role in the regulation of rapid eye movement (REM) sleep and to contribute to state-dependent respiratory depression. Nitric oxide (NO) has been shown to alter the release of acetylcholine (ACh) in a number of brain regions, and previous studies indicate that NO may participate in the modulation of sleep/wake states. The present investigation tested the hypothesis that inhibition of NO synthase (NOS) within the medial pontine reticular formation (MPRF) of the unanesthetized cat would decrease ACh release, inhibit REM sleep, and prevent cholinergically mediated respiratory depression. Local NOS inhibition by microdialysis delivery of $N^{G}$-nitro-L-arginine (NLA) significantly reduced $\mathrm{ACh}$ release in the cholinergic cell body region of the pedunculopontine tegmental nucleus and in the cholino-
\end{abstract}

ceptive mPRF. A second series of experiments demonstrated that $\mathrm{mPRF}$ microinjection of NLA significantly reduced the amount of REM sleep and the REM sleep-like state caused by mPRF injection of the acetylcholinesterase inhibitor neostigmine. Duration but not frequency of REM sleep epochs was significantly decreased by MPRF NLA administration. Injection of NLA into the mPRF before neostigmine injection also blocked the ability of neostigmine to decrease respiratory rate during the REM sleep-like state. Taken together, these findings suggest that MPRF NO contributes to the modulation of ACh release, REM sleep, and breathing.

Key words: acetylcholine; nitric oxide; pons; reticular formation; respiratory control; halothane anesthesia; REM sleep
Pontine cholinergic neurotransmission is involved in regulating the rapid eye movement (REM) phase of sleep (Steriade and McCarley, 1990; Jones, 1993; Lydic and Baghdoyan, 1994; McCarley et al., 1995). Both anatomical (Mitani et al., 1988; Shiromani et al., 1988) and functional (Lydic and Baghdoyan, 1993) studies have shown that cholinergic neurons of the laterodorsal and pedunculopontine tegmental (LDT/PPT) nuclei project axon terminals to the medial pontine reticular formation (mPRF), where acetylcholine $(\mathrm{ACh})$ is released. Electrical stimulation of the LDT/PPT causes a monotonic increase in $\mathrm{mPRF}$ ACh release (Lydic and Baghdoyan, 1993). Lesions of the LDT/PPT disrupt REM sleep, and the amount of REM sleep reduction is correlated positively with LDT/PPT cell destruction (Webster and Jones, 1988; Shouse and Siegel, 1992). Microinjection of cholinergic agonists into the mPRF elicits a state with the behavioral and electrophysiological traits of REM sleep (Baghdoyan et al., 1984; Baghdoyan et al., 1989; Vanni-Mercier et al., 1989; Yamamoto et al., 1990; Baghdoyan et al., 1993). This cholinergically evoked REM sleep-like state also is characterized by upper airway muscle hypotonia and depressed rate of breathing (Lydic and Baghdoyan, 1989; Lydic et al., 1989). ACh release in the mPRF increases during the cholinergically evoked REM sleep-like state (Lydic et al., 1991) and during natural REM sleep (Leonard and Lydic, 1995). Therefore, multiple lines of evidence have established the involvement of cholinergic LDT/PPT cells and noncholinergic,

Received July 15, 1996; revised Oct. 30, 1996; accepted Oct. 31, 1996.

This work was supported by National Heart, Lung, and Blood Institute Grant HL-40881 (R.L.) and the Departments of Neuroscience and Anatomy, and Anesthesia. We thank M. A. Fleegal and P. P. Myers for excellent technical and secretarial assistance.

Correspondence should be addressed to Prof. Ralph Lydic, Department of Anesthesia, The Pennsylvania State University, College of Medicine, Hershey, PA 17033 Copyright (C) 1997 Society for Neuroscience 0270-6474/97/170774-12\$05.00/0 cholinoceptive mPRF neurons in the generation of REM sleep and state-dependent respiratory depression. An important question for understanding the cellular and molecular regulation of REM sleep concerns the mechanisms by which pontine cholinergic neurotransmission is controlled.

Nitric oxide (NO) is a modulator of neuronal function (Garthwaite and Boulton, 1995; Zhang et al., 1995) and has been shown to alter ACh release (Prast and Philippu, 1992; Guevara-Guzman et al., 1994; Ohkuma and Kuriyama, 1994; Leonard and Lydic, 1995; Ohkuma et al., 1995; Prast et al., 1995). LDT/PPT cholinergic neurons in cat stain positively for NADPH diaphorase (Vincent et al., 1983; Mizukawa et al., 1989), which has been identified as a neuronal nitric oxide synthase (NOS) (Dawson et al., 1991; Hope et al., 1991). In rat (Kapas et al., 1994a) and rabbit (Kapas et al., 1994b), systemic inhibition of NOS alters sleep. The presence of NOS protein and mRNA in LDT/PPT neurons has been confirmed (Bredt et al., 1991), and mPRF administration of a NOS inhibitor reduces mPRF ACh release (Leonard and Lydic, 1995). These findings suggested that mPRF levels of NO might modulate pontine cholinergic neurotransmission and possibly participate in the regulation of arousal states. Therefore, the present study has expanded these earlier findings by testing the hypothesis that stereoselective inhibition of NOS in the mPRF would decrease local pontine ACh release, inhibit REM sleep, and prevent cholinergically evoked respiratory rate depression.

\section{MATERIALS AND METHODS}

\section{Animal model}

Electrodes for polygraphic monitoring of sleep and wakefulness were implanted during halothane anesthesia $\left(1-2 \%\right.$ in $\left.\mathrm{O}_{2}\right)$ in 10 adult male cats. Each cat was used for either microinjection or microdialysis experiments. For microinjection studies $(n=5$ cats), 24 gauge stainless steel guide tubes were implanted $5 \mathrm{~mm}$ above the mPRF using the stereotaxic 
coordinates $[2.0 \mathrm{~mm}$ posterior $(\mathrm{P}) ; 1.5 \mathrm{~mm}$ lateral $(\mathrm{L}) ;-5.0 \mathrm{~mm}$ horizontal (H)] of Berman (1968). For experiments involving microdialysis ( $n=5$ cats), the cranial acrylic encasement surrounding the sleep scoring electrode array was equipped with a plastic well that permitted subsequent placement of microdialysis probes into the mPRF. After recovery from surgery and before beginning microdialysis or microinjection experiments, all cats were trained for 1-2 months to sleep in the laboratory in a head-stable position. Animals were studied in this head-restrained position and all experiments strictly adhered to the National Institutes of Health guidelines for the care and use of laboratory animals (National Institutes of Health Publication No. 85-23, 1985).

\section{mPRF ACh measurement}

Microdialysis. Before in vivo mPRF dialysis, a microdialysis probe (CMA/ 10 , Acton, MA) with a polycarbonate membrane of $20 \mathrm{kDa}$ pore size was placed in a vial containing a known concentration of ACh and was perfused (CMA/100 microinjection pump) with a modified Ringer's solution, $\mathrm{pH}$ 6.0, $147 \mathrm{mM} \mathrm{NaCl} ; 4.0 \mathrm{mM} \mathrm{KCl} ; 2.4 \mathrm{mM} \mathrm{CaCl}_{2} ; 10 \mu \mathrm{M}$ neostigmine bromide (Sigma, St. Louis, MO). As demonstrated previously, (Lydic et al., 1991) $10 \mu \mathrm{M}$ neostigmine does not alter arousal state. This procedure was used to determine the preexperiment recovery of ACh by the microdialysis probe. At the conclusion of each mPRF dialysis experiment, probe recovery of ACh from a standard solution verified that in vivo measurement of changes in $\mathrm{MPRF}$ ACh release was not attributable to mechanical alteration of the probe membrane. Only data from experiments in which preexperiment in vitro probe recovery did not differ from postexperiment ACh recovery are included in this report.

For each experiment, a microdialysis probe was placed in the mPRF using stereotaxic coordinates: $\mathrm{P}=1.5-3.0 \mathrm{~mm} ; \mathrm{L}=0.8-1.5 \mathrm{~mm} ; \mathrm{H}=$ -5.0 to $-6.5 \mathrm{~mm}$; probe angle $=30^{\circ} \mathrm{P}$. The dialysis probe was perfused continuously with Ringer's solution (control) at $3 \mu \mathrm{l} / \mathrm{min}$, and endogenous ACh was recovered in $30 \mu \mathrm{l}$ dialysate samples. Each $10 \mathrm{~min} \mathrm{mPRF}$ dialysate sample was collected during unambiguously scored states of wakefulness, non-REM (NREM) sleep, or REM sleep. After 2-3 hr of sample collection during Ringer's perfusion, the probe was perfused with $10 \mathrm{mM} N^{\mathrm{G}}$-nitro-L-arginine (NLA; RBI, Natick, MA) dissolved in Ringer's. Dialysate samples again were collected during wakefulness, NREM sleep, and REM sleep for determination of mPRF ACh release in the presence of the NOS inhibitor NLA. After collection of samples during Ringer's dialysis, the mPRF was dialyzed with Ringer's containing $10 \mathrm{~mm}$ $N^{\mathrm{G}}$-nitro-D-arginine (NDA; Bachem, Torrance, CA) instead of NLA. NDA is a stereoisomer of NLA that has been shown to be less potent in its ability to inhibit NOS (Wang et al., 1993). Because NDA is a relatively inactive enantiomer of NLA, it has been suggested that NDA can serve as an effective pharmacological control for NLA administration (Griffith and Stuehr, 1995). Multiple experiments using different mPRF sites in the same animal were separated by at least $5 \mathrm{~d}$.

High performance liquid chromatography (HPLC). Each $30 \mu \mathrm{lmPRF}$ dialysate sample was injected into an HPLC system (Bioanalytical Systems, West Lafayette, IN) and carried in a $50 \mathrm{~mm} \mathrm{Na} \mathrm{NPO}_{4}$ mobile phase, $\mathrm{pH} 8.5$, at $1.0 \mathrm{ml} / \mathrm{min}$ (pressure $=13-15 \mathrm{MPa}$ ). Samples passed through an analytical separation column before entering an immobilized enzyme reactor column, where $\mathrm{H}_{2} \mathrm{O}_{2}$ was produced from ACh in stoichiometric amounts. $\mathrm{H}_{2} \mathrm{O}_{2}$ was detected at a platinum electrode with an applied potential of $500 \mathrm{mV}$ relative to an $\mathrm{Ag}^{+} / \mathrm{AgCl}$ reference electrode. The generated current created a chromatogram peak that was recorded on a flat-bed recorder and processed by a computer software program (Inject). Mean retention time for the ACh chromatogram was $5.30 \mathrm{~min}$. The chromatogram peak areas are proportional to the ACh content in each dialysis sample. Chromatogram areas were compared with a series of ACh standards (0.1-3.0 pmol) to express ACh values as pmol/10 min for each brain sample.

\section{PPT ACh measurement}

Additional microdialysis experiments in two cats examined the effect of PPT NLA delivery on ACh release within the PPT. The animals were anesthetized with halothane $\left(1-2 \%\right.$ in $\left.\mathrm{O}_{2}\right)$ delivered through a mask. Once anesthetized, cats were intubated with a \#4 cuffed endotracheal tube and placed in stereotaxic head restraint. A microdialysis probe was placed in the PPT according to the coordinates of Berman (1968): $\mathrm{P}=0.8$ $\mathrm{mm} ; \mathrm{L}=3.0 \mathrm{~mm} ; \mathrm{H}=-2.5 \mathrm{~mm}$; angle $=30^{\circ} \mathrm{P}$. The probe was constantly perfused at $3 \mu \mathrm{l} / \mathrm{min}$ with Ringer's solution. A Raman spectrophotometer sampled expired gas from the endotracheal tube and measured end tidal $\mathrm{CO}_{2}$ and halothane concentration. Halothane anesthesia was maintained at $1.2 \%\left(\right.$ in $\mathrm{O}_{2}$ ). End tidal $\mathrm{CO}_{2}$ was maintained at $20-25 \mathrm{mmHg}$ by adjusting minute ventilation. During $1.2 \%$ halothane anesthesia, $30 \mu \mathrm{l}$ dialysate samples were collected and ACh content was measured as $\mathrm{pmol} / 10 \mathrm{~min}$. After termination of halothane anesthesia, ACh released into the PPT was measured during wakefulness. Wakefulness was determined by (1) measurement of end tidal halothane; (2) polygraphic recordings (EEG desynchrony, return of muscle tone, conjugate eye movements); and (3) behavioral observation (limb movements, tracking eye movements). Finally, the microdialysis probe was perfused with $10 \mathrm{~mm}$ NLA and samples were analyzed for ACh content as a result of delivery of a NOS inhibitor during a state of quiet wakefulness. From these experiments, it was possible to quantify the effects of both $1.2 \%$ halothane anesthesia and PPT NOS inhibition on ACh release within the PPT.

\section{mPRF microinjections}

Drug administration. Because the brain parenchyma is devoid of nociceptors, it was possible to make repeated microinjections into the mPRF of unanesthetized cats while they were in a state of quiet wakefulness. Microinjections were given through 31 gauge stainless steel tubing placed in the implanted guide tube. A $250 \mathrm{nl}$ volume of saline (vehicle control) or drug was injected into the mPRF over a $30 \mathrm{sec}$ period using a $1 \mu \mathrm{l}$ Hamilton syringe (Thomas Scientific, Swedesboro, NJ) and a manual microdrive assembly. For $2 \mathrm{hr}$ after the microinjection, states of sleep and wakefulness were recorded on a Grass polygraph. A thermistor placed at the nares also permitted polygraphic quantification of respiratory rate. In this way, effects of mPRF drug administration on sleep/wake states were determined for the following six microinjection conditions: (1) saline; (2) NLA (22.8 mM: $1.25 \mu \mathrm{g} / 0.25 \mu \mathrm{l})$; (3) NDA (22.8 mM: $1.25 \mu \mathrm{g} / 0.25 \mu \mathrm{l})$; (4) neostigmine bromide (40.0 mM: $3.0 \mu \mathrm{g} / 0.25 \mu \mathrm{l}$ saline); (5) $22.8 \mathrm{~mm}$ NLA microinjected $15 \mathrm{~min}$ before a $40.0 \mathrm{~mm}$ neostigmine injection; and (6) $22.8 \mathrm{~mm}$ NDA microinjected $15 \mathrm{~min}$ before a $40.0 \mathrm{~mm}$ neostigmine injection. In addition, respiratory rate was quantified after $\mathrm{mPRF}$ injection of saline; $40.0 \mathrm{~mm}$ neostigmine alone; $22.8 \mathrm{~mm}$ NLA $15 \mathrm{~min}$ before neostigmine; and $22.8 \mathrm{~mm}$ NDA before neostigmine. All experiments in which a drug (NLA, NDA, or neostigmine) were microinjected into the mPRF of the same animal were separated by at least $3 \mathrm{~d}$.

State and breathing quantification. For each experiment, $2 \mathrm{hr}$ polygraphic recordings were divided into 120 bins, and each min was scored as wakefulness, NREM sleep, or REM sleep. Polygraphic variables recorded from the implanted electrodes were used to objectively score states of wakefulness, NREM sleep, and REM sleep according to standard criteria (Ursin and Sterman, 1981). For each recording, 10 min of each of the three states was randomly selected and respiratory rate (breaths/min) was tabulated.

\section{Data analysis}

For microdialysis and microinjection experiments, descriptive statistics and ANOVA were used to quantify drug effects on the following dependent measures: $\mathrm{mPRF}$ and PPT ACh release (pmol/10 min); percent wakefulness, NREM sleep, and REM sleep; REM sleep latency; REM sleep epoch frequency and duration; and rate of breathing. Post hoc multiple pairwise comparisons were performed using Tukey's tests for analysis of state effect on mPRF and PPT ACh release. For mPRF microdialysis experiments, $a$ priori independent $t$ tests were used to test for statistical significance in the difference between $\mathrm{ACh}$ release during control (Ringer's) or drug (10 mM NLA or $10 \mathrm{~mm}$ NDA) dialysis within states of wakefulness, NREM sleep, and REM sleep. To test the effects of mPRF microinjection on the percent time spent in REM sleep, NREM sleep, and wakefulness; REM sleep epoch duration, frequency, and latency; as well as injection effect on respiratory rate within each state, multiple pair-wise comparisons were made using independent $t$ tests with Bonferroni correction factors ( $p_{\text {actual }}=0.05 /$ number of comparisons). From four of the five animals, it was possible to obtain three measures of breathing and arousal state in each of the six microinjection conditions. From the fifth animal, three measures of breathing and arousal state were obtained for four of the six microinjection conditions. For all statistical comparisons, a significance level of $p=0.05$ was chosen.

\section{Histological analysis}

At the completion of mPRF microdialysis or microinjection experiments, cats were deeply anesthetized with sodium pentobarbital and transcardially perfused with isotonic saline followed by $10 \%$ phosphate buffered formalin, pH 7.0, (Fisher Scientific, Houston, TX). Brains were removed and soak-fixed first in the buffered formalin and then in 30\% sucroseformalin for 1-2 weeks. Brainstems were sectioned (40 $\mu \mathrm{m}$ thick) on a 
freezing microtome, mounted on chrome-alum-coated slides, stained with cresyl violet, and coverslipped.

\section{RESULTS}

The results were obtained from a total of $1870 \mathrm{~min}$ of $\mathrm{mPRF}$ microdialysis, $330 \mathrm{~min}$ of PPT microdialysis, and $82 \mathrm{mPRF}$ microinjection experiments. These data are the first to show the ability of NOS inhibition within specific brain regions to alter simultaneously (1) neurotransmitter release, (2) states of sleep and wakefulness, and (3) state-dependent respiratory depression. Portions of these mPRF microdialysis data were published previously in a brief report (Leonard and Lydic, 1995). The present results describe for the first time an increased number mPRF dialysis samples, ACh release from PPT brain regions, the stereoselective effects of NLA, and the ability of mPRF NOS inhibition to alter REM sleep and breathing during REM sleep.

\section{Identification of microdialysis and microinjection sites}

For all microdialysis experiments, confirmation of dialysis probe placement in the mPRF and the PPT was achieved by successful in situ recovery of $\mathrm{ACh}$ and histological visualization of probeinduced lesions. Figure 1, $A$ and $B$, demonstrates visualization and localization of probe-induced lesions within the MPRF and the PPT, respectively. Likewise, stereotaxic placement of microinjectors in the mPRF was verified by histological analyses. For all microinjection studies, a $3 \mu \mathrm{g}$ injection of neostigmine was able to cause a REM sleep-like state (Baghdoyan et al., 1984) during at least $50 \%$ of a $2 \mathrm{hr}$ recording period. A typical mPRF microinjection lesion is illustrated in Figure $1 C$.

\section{MPRF ACh release varied across states}

\section{MPRF ACh release during states of sleep and wakefulness}

To test the hypothesis that ACh release in the mPRF would increase during REM sleep relative to NREM sleep and wakefulness ACh levels, $10 \mathrm{~min}(30 \mu \mathrm{l}) \mathrm{mPRF}$ dialysate samples $(n)$ were collected during objectively defined states of wakefulness $(n=$ $41)$, NREM sleep $(n=33)$, and REM sleep $(n=18)$ from five different cats. Quantification of these samples revealed statedependent differences in mPRF ACh release $\left(F_{(2,92)}=42.10 ; p<\right.$ $0.0001)$ (Fig. $2 A$, hatched bars). During REM sleep, mPRF ACh release increased significantly, rising $100 \%$ over waking levels and $124 \%$ above ACh release during NREM sleep. In every experiment in each animal, mPRF ACh release measured during REM sleep was at least $80 \%$ greater than ACh release during either wakefulness or NREM sleep. There was no significant difference in ACh levels recovered from the mPRF comparing wakefulness and NREM sleep (post hoc Tukey's test).

\section{NLA decreased MPRF ACh release}

To test the hypothesis that NO regulates pontine ACh release, the mPRF of intact, unanesthetized cats was dialyzed with the NOS inhibitor NLA while simultaneously measuring ACh release during wakefulness, NREM sleep, and REM sleep. Figure $2 A$ shows that during every state, NLA caused a significant reduction in mean mPRF ACh release. Compared with Ringer's dialysis, NLA caused decreases in average mPRF ACh release of $39 \%$ during wakefulness $(t=6.01 ; \mathrm{df}=74 ; p<0.0001) ; 44 \%$ decrease during NREM sleep $(t=4.47$; df $=61 ; p<0.0001)$; and $45 \%$ during REM sleep $(t=3.52$; df $=27 ; p=0.0016)$.

During NLA dialysis, state-dependent changes in mPRF ACh release also were observed $\left(F_{(2,76)}=12.82 ; p<0.0001\right)$ (Fig. $2 A$, solid bars). REM sleep ACh release $(n=11)$ was significantly greater than wakefulness ACh release ( $82 \%$ increase) and NREM

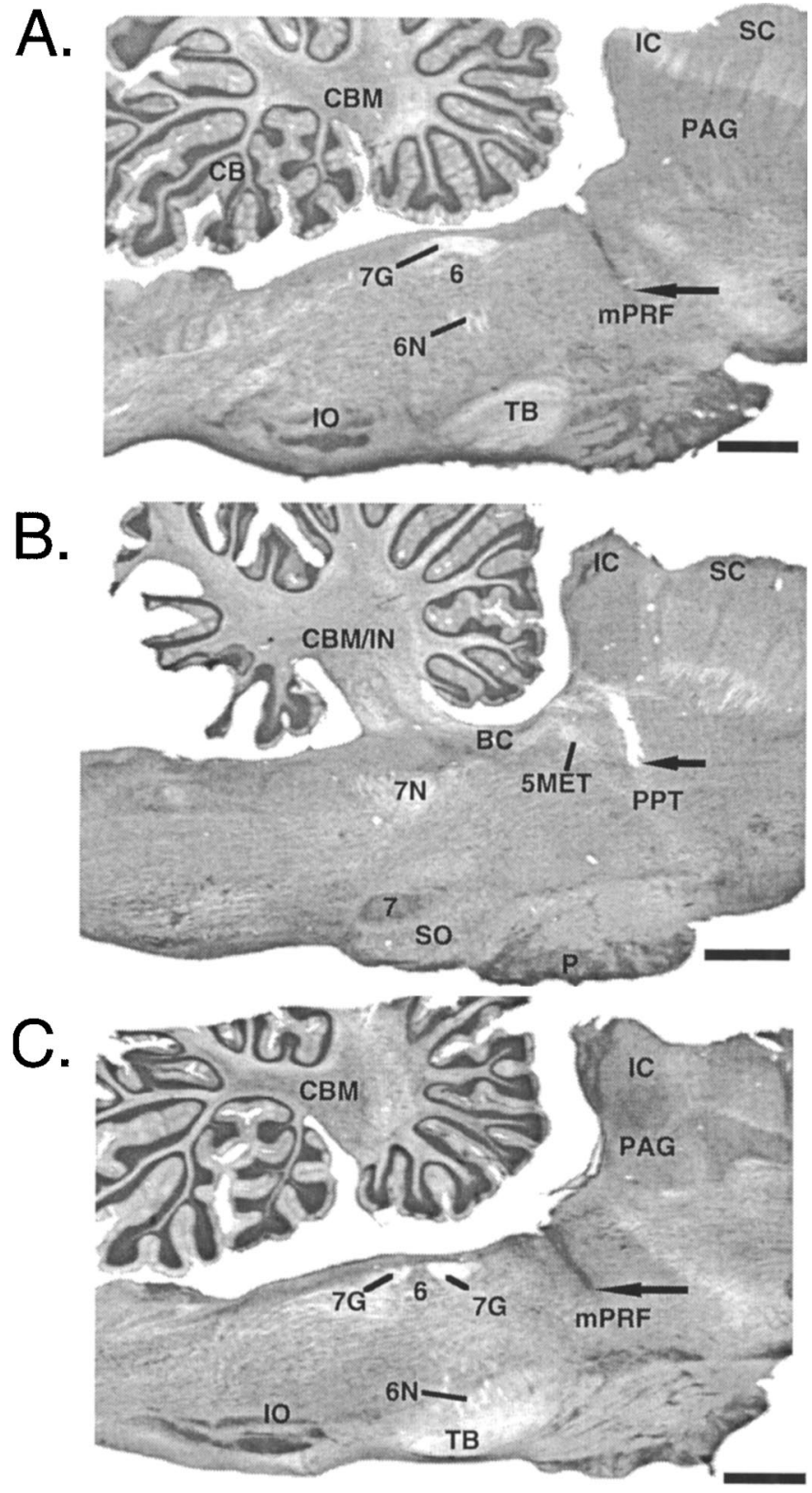

Figure 1. Sagittal sections of cat brainstem stained with cresyl violet and showing histological localization of representative microdialysis and microinjection sites. Rostral is to the right. A, The black arrow marks the tip of the lesion in the mPRF (also referred to as the gigantocellular tegmental field, or FTG, by Berman, 1968) caused by the microdialysis probe. The tip of the lesion was localized to the coordinates $\mathrm{P}=3.0 \mathrm{~mm} ; \mathrm{L}=1.5 \mathrm{~mm}$; $\mathrm{H}=-5.5 \mathrm{~mm}$. $B$, Cat brainstem cut through the PPT nuclei at $2.9 \mathrm{~mm}$ lateral to midline. The tip of the microdialysis probe lesion is located at $\mathrm{P}=0.5 \mathrm{~mm}$ and $\mathrm{H}=-2.5 \mathrm{~mm}$ and is indicated by the black arrow. $C$, Brainstem section illustrating a microinjection site in the cat mPRF (black arrow) localized to $\mathrm{P}=2.0 \mathrm{~mm} ; \mathrm{L}=1.6 \mathrm{~mm} ; \mathrm{H}=-6.0 \mathrm{~mm}$. Scale bars (lower right corners), $A-C, 2 \mathrm{~mm}$. 5MET, Mesencephalic trigeminal tract; 6 , abducens nucleus; $6 N$, abducens nerve; 7 , facial nucleus; $7 G$, genu of facial nerve; $7 N$, facial nerve; $B C$, brachium conjunctivum; $C B$, cerebellar cortex; $C B M$, medial nucleus of the cerebellum; $C B M / I N$, medial and interpositus nuclei of the cerebellum; $I C$, inferior colliculus; $I O$, inferior olive; $m P R F$, medial pontine reticular formation (or FTG); $P$, pyramidal tract; $P A G$, periaqueductal gray; $S C$, superior colliculus; $S O$, superior olive; $T B$, trapezoid body. 


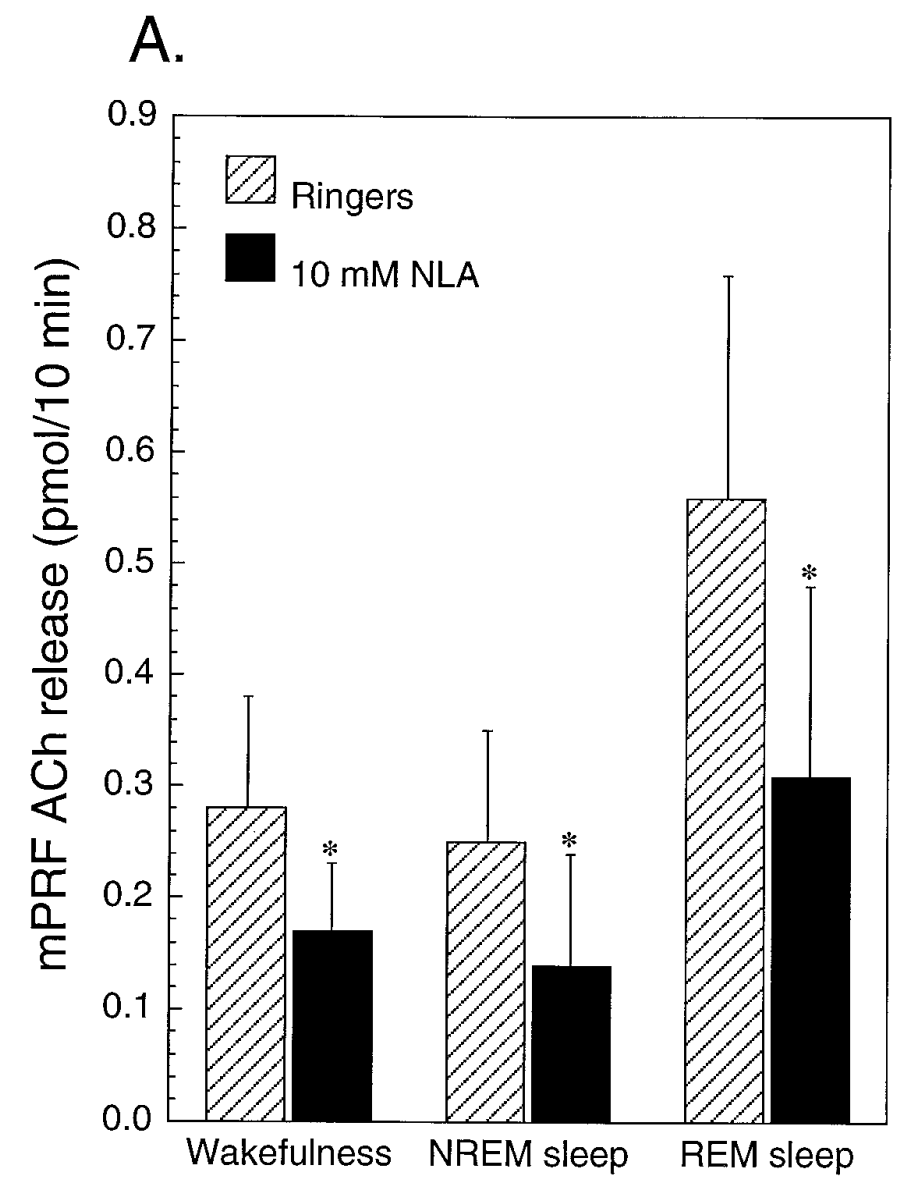

B.

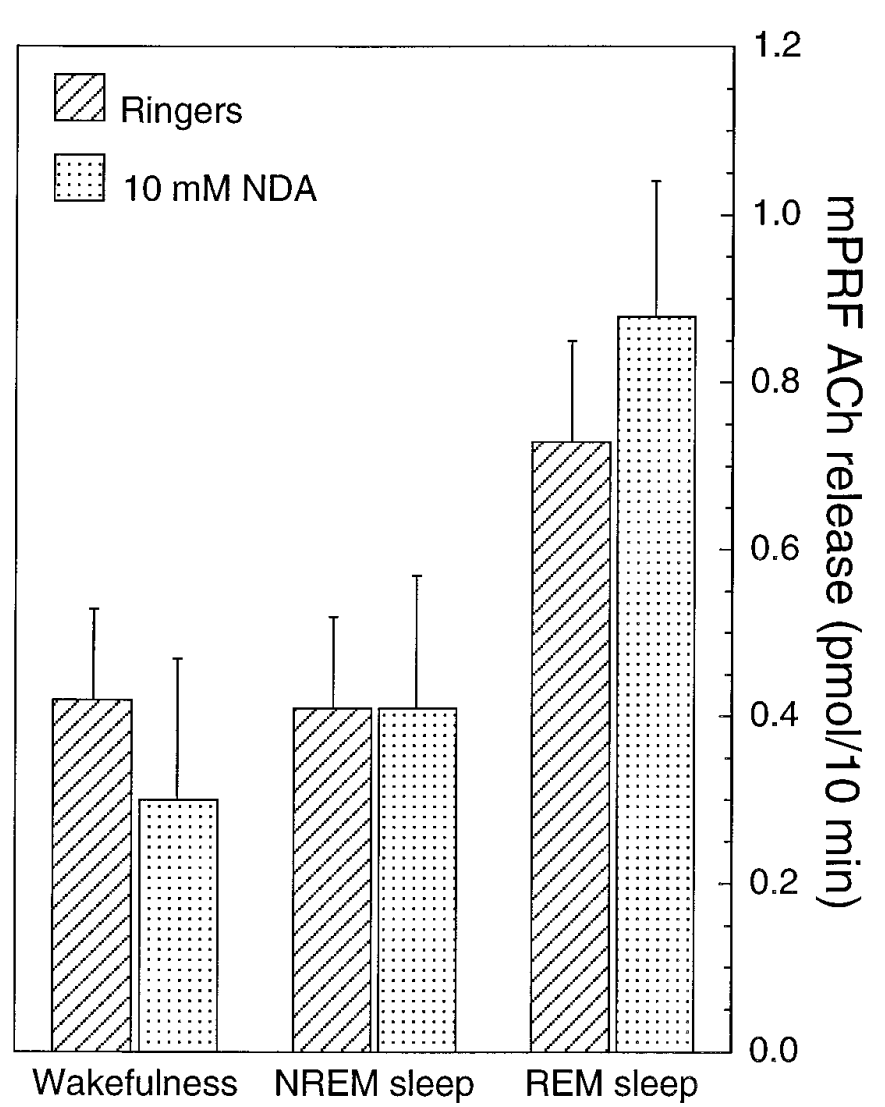

Figure 2. NLA dialysis significantly reduced mPRF ACh release compared with Ringer's control. $A$, mPRF ACh release while dialyzing the mPRF with Ringer's (control, hatched bars) or 10 mM NLA (solid bars) during wakefulness, NREM sleep, and REM sleep. Values on the ordinate are expressed as mean $+\mathrm{SD}$ pmol of ACh recovered from the mPRF per $10 \mathrm{~min}$ of dialysis. Asterisks designate a significant difference $(p<0.05$; independent $t$ tests) in mean mPRF ACh release between NLA dialysis and Ringer's dialysis within each state. $B$, Mean + SD mPRF ACh release from separate experiments dialyzing the mPRF with either Ringer's solution (control, hatched bars) or 10 mM NDA (stippled bars) during states of wakefulness, NREM sleep, or REM sleep. Note that NDA, the less active stereoisomer of NLA, had no statistically significant effect on mPRF ACh release compared with Ringer's control.

sleep ACh values (121\% increase). Average ACh release during wakefulness ( $n=35$ samples) was not significantly different from NREM sleep ACh release $(n=30)$.

$M P R F$ ACh release was not altered by dialysis with $N D A$ Additional microdialysis experiments were designed to confirm that mPRF administration of NLA decreased mPRF ACh release because of specific enzymatic inhibition of NOS. These experiments involved dialyzing the mPRF with $10 \mathrm{~mm}$ NDA, the less active stereoisomer of NLA. Figure $2 B$ shows that compared with control, NDA did not significantly alter mPRF ACh release during wakefulness, NREM sleep, or REM sleep. Dialysis with NDA also did not produce any observable behavioral or electrographic effects on states of arousal.

\section{PPT ACh release was decreased by halothane anesthesia and PPT NOS inhibition}

Halothane anesthesia has been shown to decrease ACh release from cholinergic terminals in the mPRF (Keifer et al., 1994). Additionally, stereoselective NOS inhibition now has been shown to decrease ACh release within the mPRF (Fig. 2). Because the mPRF is known to contain PPT axon terminals, these results encouraged experiments designed to test the hypothesis that halothane and NLA would decrease ACh release in the cholinergic cell body region of the PPT. Figure $3 A$ illustrates chromatogram peaks representative of PPT ACh release during 1.2\% halothane anesthesia (left), during quiet wakefulness with Ringer's dialysis (middle), and during quiet wakefulness while dialyzing the PPT with $10 \mathrm{~mm}$ NLA (right). Figure $3 B$ shows that both $1.2 \%$ halothane and delivery of the NOS inhibitor NLA during wakefulness caused a significant decrease in PPT ACh release compared with ACh levels of release during quiet wakefulness with Ringer's dialysis. Mean ( $\pm \mathrm{SD})$ ACh release $(\mathrm{pmol} / 10 \mathrm{~min})$ in the PPT was reduced $15 \%(p<0.05)$ by $1.2 \%$ halothane anesthesia $(n=11)$ compared with wakefulness $(n=10)$. PPT ACh release was decreased by $36 \%(p<0.01)$ with NLA dialysis $(n=11)$ during quiet wakefulness compared with ACh levels of release during Ringer's dialysis. The reduction in PPT ACh release caused by NLA was greater than the reduction caused by $1.2 \%$ halothane anesthesia ( $p<0.01$, post hoc Tukey's test).

\section{mPRF microinjection of NOS inhibitor decreased REM sleep}

Having demonstrated that NLA significantly decreased mPRF ACh release (Fig. 2), and knowing that REM sleep is generated, in part, by cholinergic stimulation of the mPRF, this study also tested the hypothesis that mPRF NLA microinjection would de- 


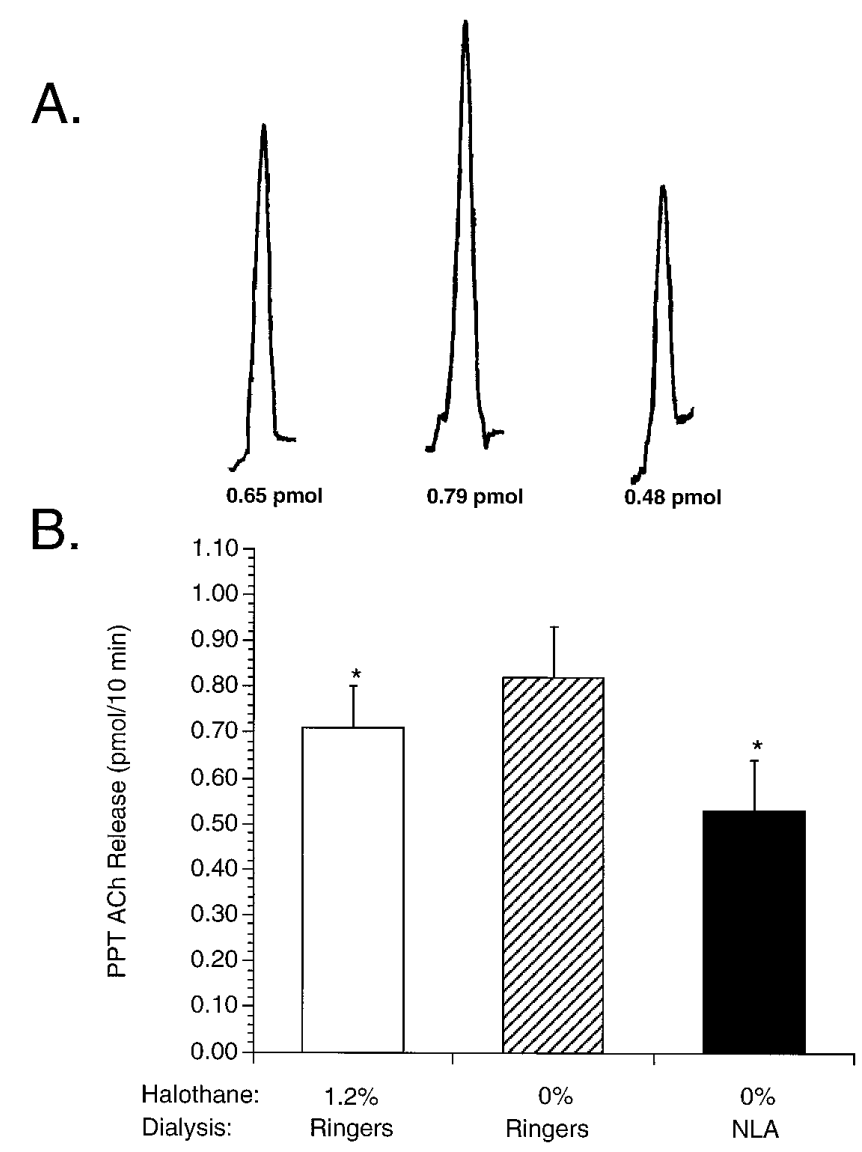

Figure 3. Both $1.2 \%$ halothane and PPT NLA dialysis decreased PPT ACh release. $A$, Chromatograms show peak areas proportional to ACh content present in $30 \mu \mathrm{l}(10 \mathrm{~min})$ dialysate samples indicating PPT ACh release under three different conditions. The chromatogram to the far left is representative of PPT ACh release during 1.2\% halothane anesthesia while dialyzing with Ringer's. The center peak shows ACh release during quiet wakefulness with Ringer's dialysis. The effect of NLA dialysis on ACh release during quiet wakefulness is illustrated on the far right. The numbers below each chromatogram indicate the amount of ACh (pmol/10 min). B, Mean + SD PPT ACh release is shown on the ordinate during administration of $1.2 \%$ halothane with Ringer's dialysis (open bar) during wakefulness ( $0 \%$ halothane) with Ringer's dialysis (hatched bar) and during wakefulness in the presence of NLA dialysis (solid bar). There was a significant main effect of dialysis and anesthetic condition on PPT ACh release $\left(F_{(2.32)}=23.59 ; p<0.0001\right)$. Asterisks indicate significantly decreased $(p<0.05$; Tukey's test) ACh release during $1.2 \%$ halothane and NLA dialysis.

crease natural REM sleep and would block the neostigmineinduced REM sleep-like state (Baghdoyan et al., 1984). Figure 4 shows polygraphic recordings obtained from the present experiments demonstrating the electrographic traits of wakefulness, NREM sleep, REM sleep, and the REM sleep-like state induced by $3 \mu \mathrm{g}$ neostigmine mPRF injection (REM-Neo). Figure 5 illustrates the typical patterns of waking, NREM sleep, and REM sleep states during 120 min after mPRF microinjection for six different microinjection conditions. The Figure 5 data also show the ability of neostigmine and NLA to alter the temporal organization of REM sleep

\section{MPRF microinjection of NLA, but not NDA, inhibited REM sleep}

Figure 6 illustrates the effect of mPRF microinjection of saline (control), NLA, or NDA on the percent of time spent in states of sleep and wakefulness during the first $2 \mathrm{hr}$ after mPRF microin- jection. The NOS inhibitor NLA significantly reduced the time spent in REM sleep (Fig. 6A) compared with saline $(t=4.22$; df $=19 ; p<0.01$; Bonferroni correction applied) and compared with NDA $(t=4.11$; df $=19 ; p<0.01)$. NDA microinjection, however, had no effect on REM sleep percentage compared with control. There was no significant effect of mPRF microinjection of NLA or NDA on the percent time spent in NREM sleep (Fig. 6B) or wakefulness (Fig. 6C).

\section{MPRF microinjection of NLA, but not NDA, blocked the REM-Neo state}

Figure $7 A$ shows the ability of mPRF NLA to block the REM-Neo state. Compared with saline control, neostigmine injection caused a $408 \%$ increase in the percent time occupied by the REM sleep-like state $(t=13.36$; df $=26 ; p<0.01)$. NLA injected 15 min before neostigmine significantly reduced the neostigmineinduced REM sleep-like state by $64.2 \%(t=6.71$; $\mathrm{df}=28 ; p<$ 0.01 compared with Neo alone). NDA pretreatment, however, had no effect on neostigmine's ability to cause an increase in REM sleep percentage. Figure 7, $B$ and $C$, shows that the REM sleepenhancing effect of Neo occurred with a concomitant decrease in NREM sleep, not wakefulness. Figure $7 B$ shows that significantly less time was spent in NREM sleep $(-49.2 \%)$ after Neo compared with saline $(t=21.96$; df $=26 ; p<0.01)$. NLA injected before neostigmine significantly blocked $(47.2 \% ; t=4.10$; df $=$ $28 ; p<0.01)$ the neostigmine-induced decrease in NREM sleep. NREM sleep time after NLA/Neo injections still was significantly less $(-26 \%)$ than after saline injection $(t=4.71$; df $=26 ; p<$ $0.01)$. NDA pretreatment did not alter the neostigmine-induced decrease in NREM sleep. Figure $7 C$ shows that there was no effect of Neo, NLA/Neo, or NDA/Neo injections on time spent in wakefulness.

\section{mPRF microinjection of NLA, but not NDA, altered the temporal organization of REM sleep}

Figure 8 illustrates the effect of mPRF microinjection on both the frequency and duration of REM sleep epochs. There was a statistically significant main effect of mPRF microinjection on the mean duration of REM sleep epochs $\left(F_{(5,404)}=8.30 ; p<0.0001\right)$ and the number of REM sleep epochs over a $2 \mathrm{hr}$ period $\left(F_{(5,73)}\right.$ $=5.25 ; p=0.0004)$. Independent $t$ test comparisons revealed that mean REM sleep epoch duration after NLA injection was reduced significantly ( $-60 \%)$ compared with saline (NLA vs saline), whereas NDA had no effect on REM sleep duration (NDA vs saline). Neostigmine injection significantly increased REM sleep epoch duration $(+103 \%)$ compared with saline (Neo vs saline). NLA administration before neostigmine completely blocked the epoch duration enhancement induced by neostigmine (NLA/Neo vs Neo) and returned the REM sleep epoch duration to control levels (NLA/Neo vs saline). NDA pretreatment had no effect on the REM sleep epoch duration enhancement caused by neostigmine (NDA/Neo vs Neo). Compared with saline, neostigmine injection significantly increased $(+155 \%)$ the number of REM sleep epochs (Neo vs saline). Neither NLA nor NDA pretreatment affected the ability of neostigmine to enhance the number of REM sleep epochs (NLA/Neo or NDA/Neo vs Neo). Injection of NLA or NDA alone did not alter the frequency of naturally occurring REM sleep epochs (NLA or NDA vs saline). Taken together, these data show that mPRF NLA injection had selective effects on the temporal organization of REM sleep, causing a significant decrease in the duration, but not the number, of REM sleep and REM-Neo episodes. 

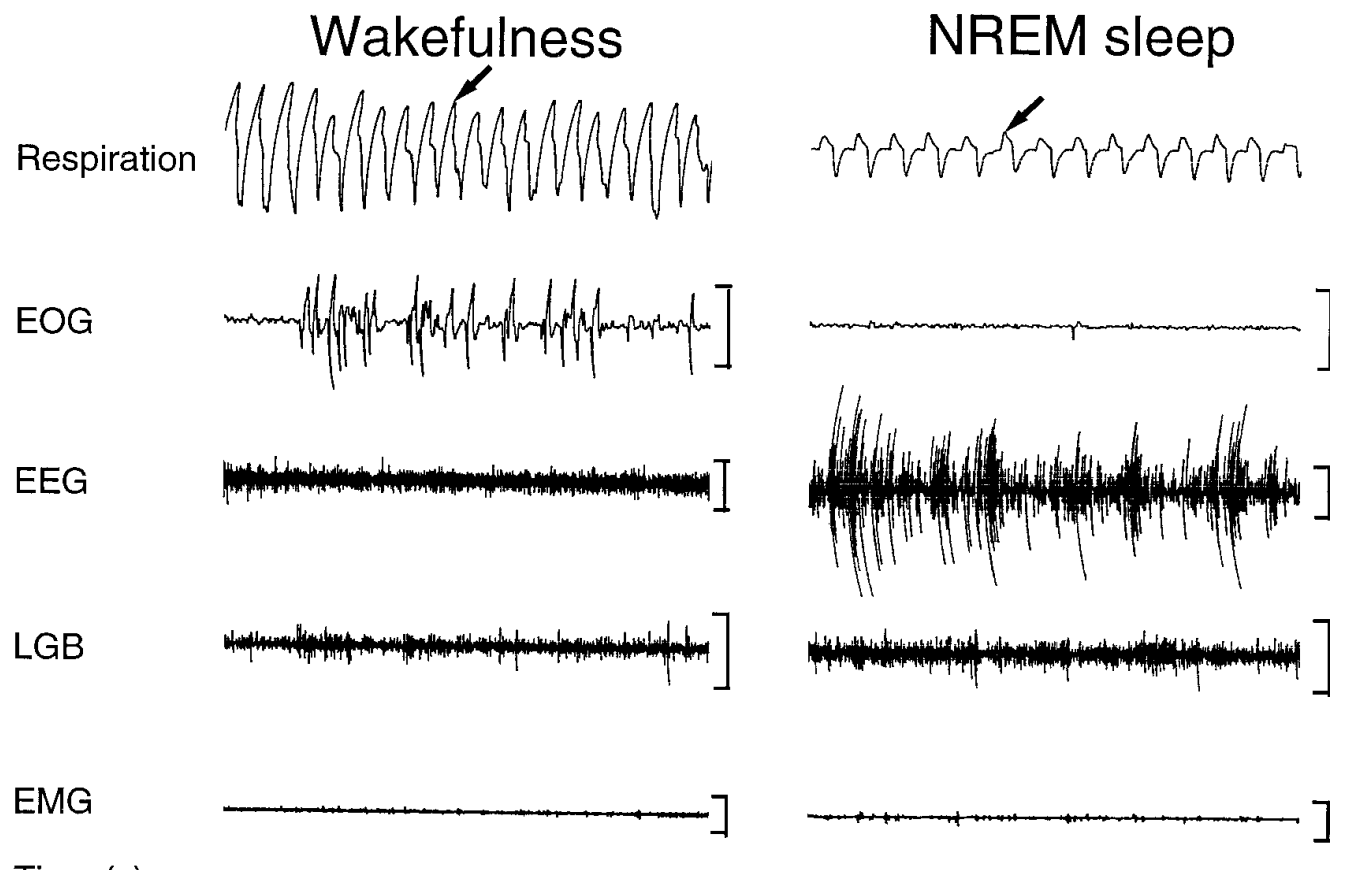

Time (s)

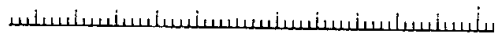
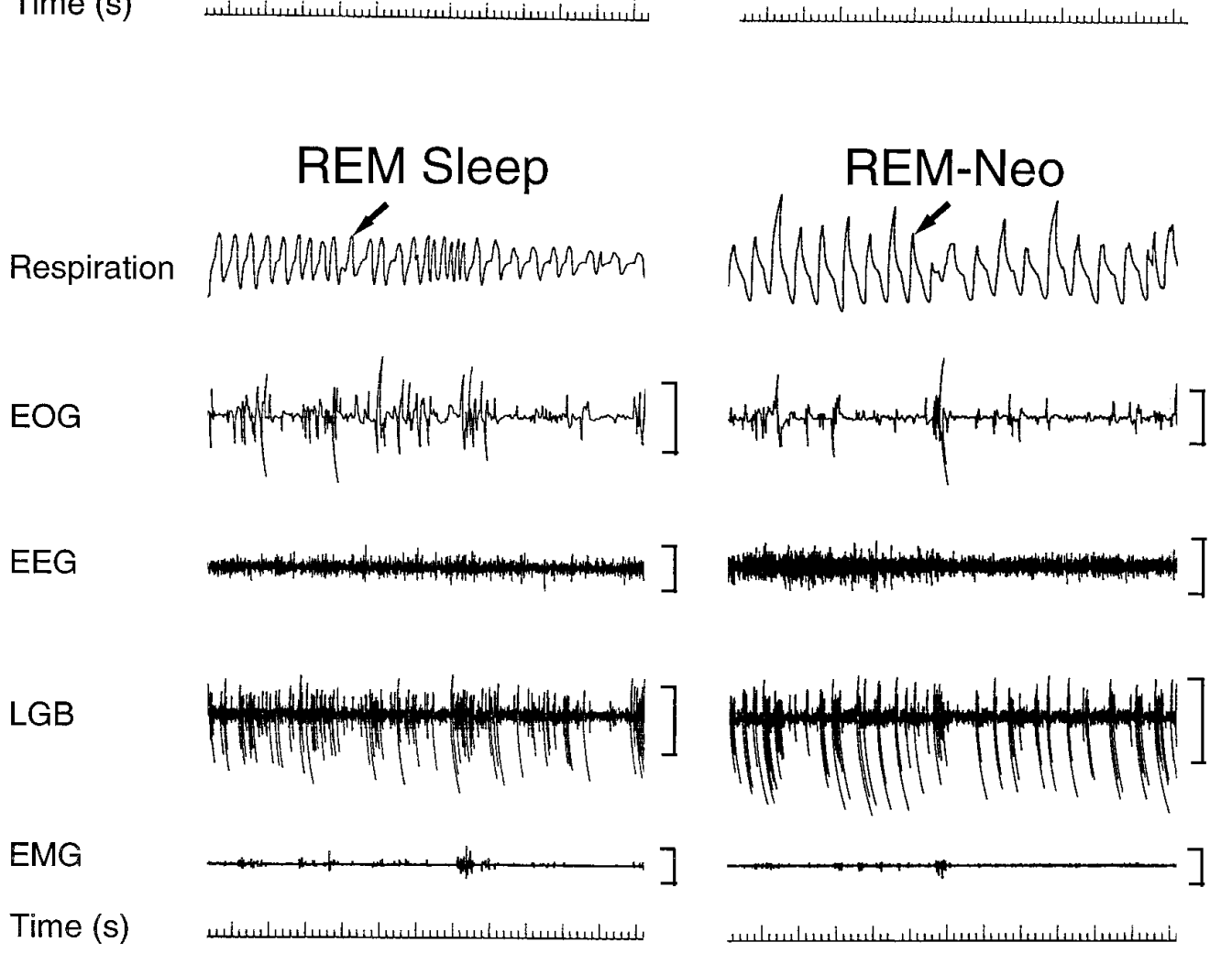

Figure 4. One minute samples of polygraphic recordings during states of wakefulness, NREM sleep, REM sleep, and the REM sleep-like state induced by $\mathrm{mPRF}$ microinjection of neostigmine (REM-Neo). During each state, polygraphic tracings record respiration (arrow marks a point of peak inspiratory airflow), eye movements $(E O G)$, cortical electroencephalogram $(E E G)$, field potentials from the lateral geniculate body of the thalamus $(L G B)$, and neck muscle electromyogram $(E M G)$. Time scale (each tick equals $1 \mathrm{sec}$ ) is shown at the bottom of each 1 min polygraphic record. Calibration bars show amplitude of pen deflection equal to $100 \mu \mathrm{V}$. Note that during REM-Neo, the REMs, EEG activation, presence of ponto-geniculo-occipital waves in the LGB recording, and muscle atonia interrupted by periodic bursts of muscle activity are similar to those seen during natural REM sleep.

\section{mPRF microinjection of NLA, but not NDA, altered respiratory rate}

The ability of mPRF NLA injection to block the cholinergically induced decrease in respiratory rate during the REM sleep state is illustrated in Figure 9. In agreement with previously described effects of mPRF carbachol (Lydic and Baghdoyan, 1989) and bethanechol (Lee et al., 1995) on respiratory rate, mPRF injection of neostigmine caused a significant reduction in respiratory rate 
A. Saline

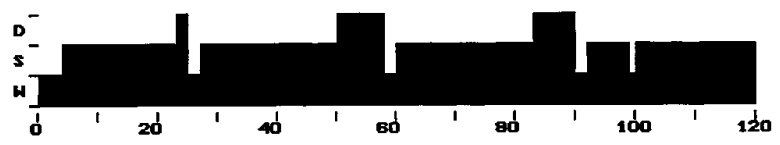

B. $1.25 \mu \mathrm{g} \mathrm{NLA}$

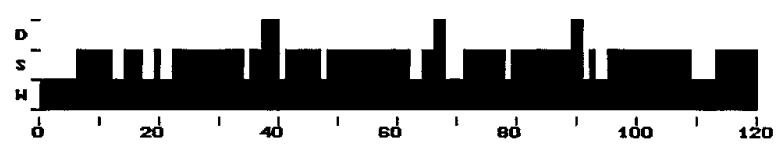

C. $1.25 \mu \mathrm{g} \mathrm{NDA}$

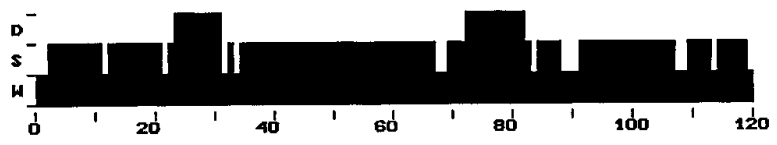

D. $3.0 \mu \mathrm{g}$ Neostigmine

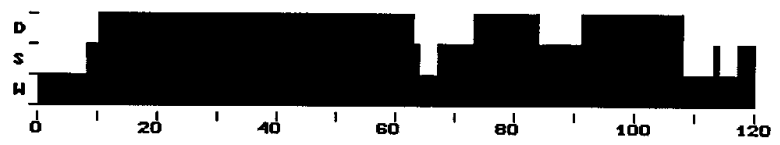

E. $1.25 \mu \mathrm{g} \mathrm{NLA} / 3.0 \mu \mathrm{g}$ Neostigmine

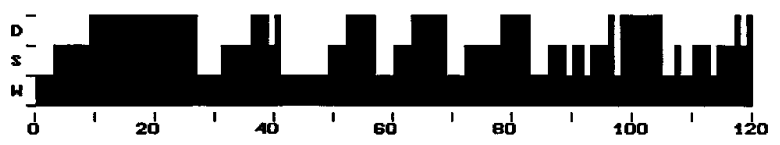

F. $1.25 \mu \mathrm{g} \mathrm{NDA} \mathrm{/} 3.0 \mu \mathrm{g}$ Neostigmine

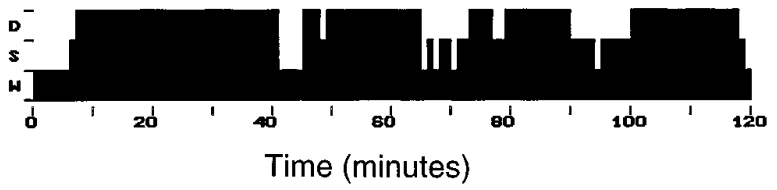

Figure 5. Time course of sleep and wakefulness after mPRF microinjection. For each minute of the $2 \mathrm{hr}$ polygraphic recording (shown on the abscissa), the behavioral state is indicated as wakefulness [ $W$ (lowest level), NREM sleep ( $S=$ EEG Synchronization, middle level), or REM sleep $(D=$ EEG $D$ esynchronization, highest level)] on the ordinate. These plots illustrate typical sleep/wake patterns for $120 \mathrm{~min}$ after each of six different mPRF microinjection conditions $(A-F)$. Note the increase in REM sleep time evoked by Neo injection ( $D$ vs $A$ ). Note also the ability of the NOS inhibitor NLA to decrease both natural REM sleep ( $B$ vs $A$ ) and the REM sleep-like state induced by neostigmine ( $E$ vs $D)$. NDA had no effect on natural ( $C$ vs $A$ ) or neostigmine-induced ( $F$ vs $D$ ) REM sleep. These plots also illustrate how the temporal organization of REM sleep was quantified for (1) REM sleep latency (the time from mPRF injection at min 0 to the onset of the first REM sleep episode: $22 \mathrm{~min}$ in plot $A$ ); (2) REM sleep epoch frequency (the number of REM sleep epochs that occurred over $2 \mathrm{hr}$ : 3 for plot $A$ ); and (3) duration of individual REM sleep epochs $(2,4$, and $3 \mathrm{~min}$ for plot $A)$.

during REM sleep compared with saline control $(t=6.50$; $\mathrm{df}=$ 262; $p<0.01$; Bonferroni correction). NLA injection before neostigmine completely blocked the ability of neostigmine to decrease respiratory rate. NDA injection before neostigmine did not alter the neostigmine-induced decrease in respiratory rate.

\section{DISCUSSION}

The results demonstrate that $\mathrm{mPRF}$ administration of the NOS inhibitor NLA stereoselectively (1) decreased ACh release within the mPRF, (2) inhibited REM sleep, and (3) prevented the
A.

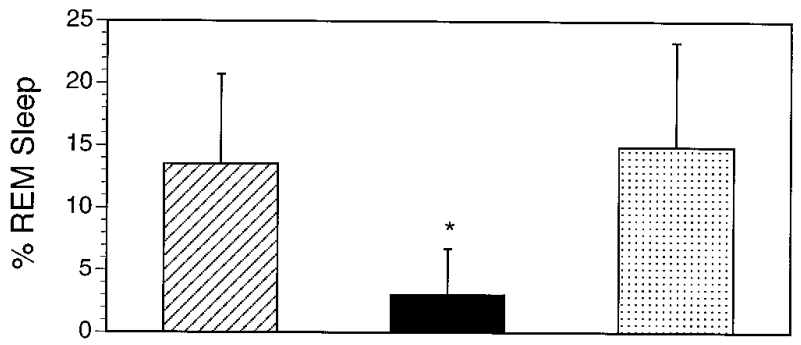

B.

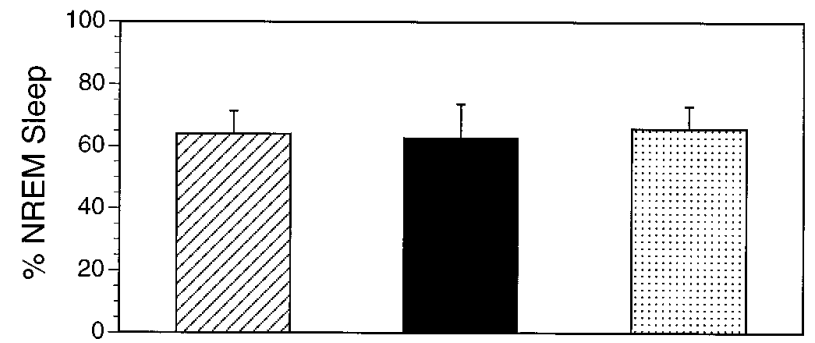

C.

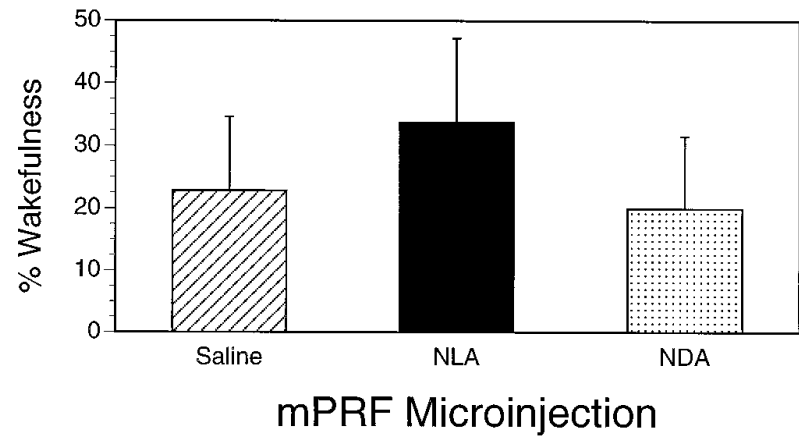

Figure 6. Effect of mPRF microinjection of $22.8 \mathrm{~mm}$ NLA or $22.8 \mathrm{~mm}$ NDA on percent time spent in REM sleep $(A)$, NREM sleep $(B)$, or wakefulness $(C)$ over a $2 \mathrm{hr}$ polygraphic recording period. Percent time (mean $+\mathrm{SD}$ ) spent in each state after microinjection of saline (control, hatched bars), NLA (solid bars), or NDA (stippled bars) is shown on the ordinate. NLA microinjection caused a 71\% decrease in REM sleep time but did not significantly alter the percent time spent in either NREM sleep or wakefulness. Microinjection of NDA had no effect on the amount of time spent in REM sleep, NREM sleep, and wakefulness; ${ }^{*} p<0.01$ (independent $t$ tests).

cholinergically induced decrease in respiratory rate during the REM sleep-like state. These are the first data to suggest that NO, produced within a specific brain region, the mPRF, altered sleep/ wake states by modulating the release of a specific neurotransmitter, ACh.

\section{Local inhibition of NOS reduced pontine $\mathrm{ACh}$ release}

Delivery of NLA to the mPRF by microdialysis caused a stereoselective decrease in mPRF ACh release. Although stereoisomers of NOS inhibitors have been shown to produce weakly some of the effects of NOS inhibition (Wang et al., 1991, 1993, 1994a), many investigators have used the D-enantiomer of NLA (referred to here as NDA) to demonstrate that the biological activity of NLA is attributable to specific interaction with NOS and inhibition of NO production (Liu et al., 1991; Iadecola, 1992; Khalil and Helme, 1992; Khanna et al., 1993; Tanaka et al., 1994; Wang et al., 1994b; Fukuto and Chaudhuri, 1995; Griffith and Stuehr, 1995). Therefore, the ability of NLA, but not the enantiomer NDA, to significantly decrease ACh release within the mPRF (Fig. 2) suggests that NO produced in the mPRF plays a role in regulating mPRF ACh release. 
A.

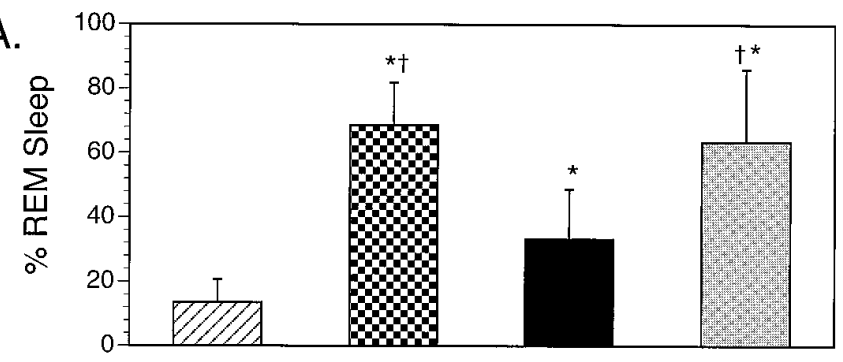

B.

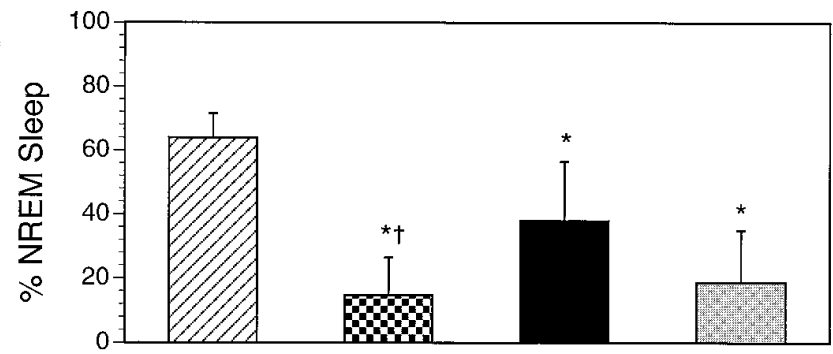

C.

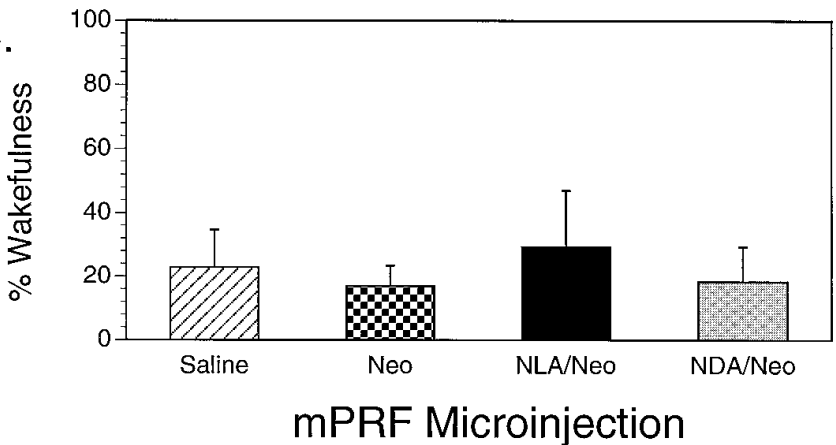

Figure 7. Effect of NLA or NDA mPRF microinjections on the ability of mPRF neostigmine (Neo) microinjection to increase the amount of time spent in a REM sleep-like state over a $2 \mathrm{hr}$ period. The ordinate shows percent of time (mean $+\mathrm{SD}$ ) spent in a polygraphically defined REM sleep state $(A)$, NREM sleep $(B)$, or wakefulness $(C)$ after microinjection of saline, $40 \mathrm{~mm}$ Neo, $22.8 \mathrm{~mm}$ NLA pretreatment to Neo (NLA/Neo), or $22.8 \mathrm{~mm}$ NDA pretreatment to Neo $(\mathrm{NDA} / \mathrm{Neo})$. Neo microinjection increased the amount of time spent in REM sleep $(A)$, while decreasing NREM sleep time $(B)$. NLA pretreatment $(N L A / N e o)$ significantly attenuated the ability of Neo to enhance REM sleep time $(A)$ and decrease NREM sleep percentage $(B)$. NDA pretreatment did not alter the effect of Neo on REM sleep and NREM sleep time. $(C)$ None of the mPRF microinjections produced a significant effect on the percent time spent in wakefulness compared with saline control. Asterisks indicate significant difference compared with saline $(p<0.01$; independent $t$ tests, Bonferroni correction); $\dagger$, significant difference from NLA/Neo injections $(p<$ $0.05)$.

$\mathrm{ACh}$ is released in the mPRF from terminals of cholinergic LDT/PPT neurons (Lydic and Baghdoyan, 1993), and the activity of these neurons is known to be important in the generation of cortical activation characterizing both REM sleep and waking states (Webster and Jones, 1988; El Mansari et al., 1990; Steriade et al., 1990; Kayama et al., 1992). Synaptically mediated, inhibitory modulation of cholinergic LDT/PPT neurons is effected by the neurotransmitters serotonin (Luebke et al., 1992; Leonard and Llinas, 1994), norepinephrine (Williams and Reiner, 1993), and ACh (Luebke et al., 1993; Leonard and Llinas, 1994). The presence of reciprocal cholinergic innervation by cholinergic LDT/PPT neurons (Semba and Fibiger, 1992; Steininger et al., 1992) suggests that the release of ACh in the LDT/PPT cholinergic cell body region might serve to modulate the activity of these

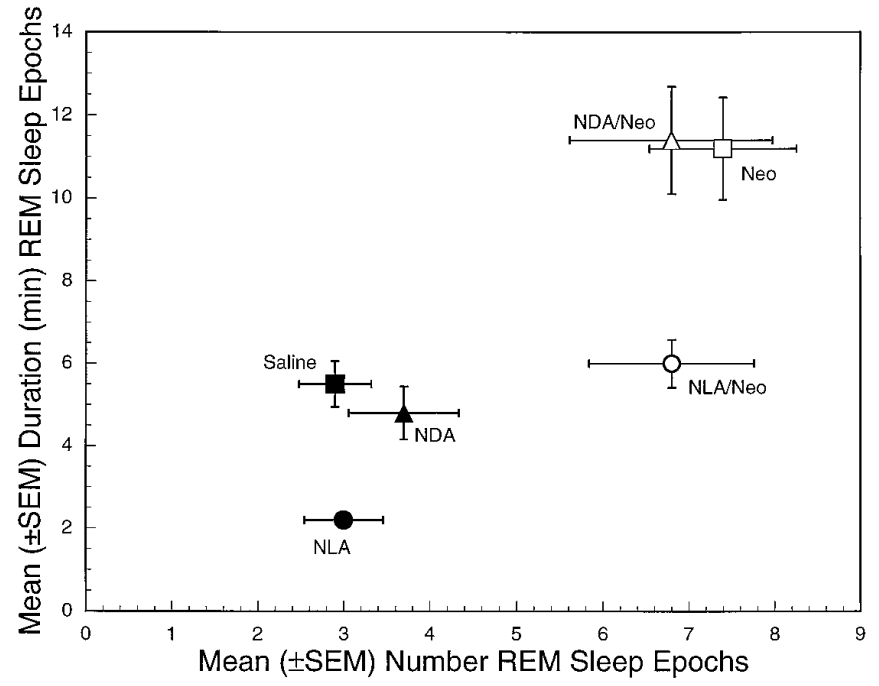

Figure 8. mPRF NLA injection disrupted the maintenance of REM sleep but not the initiation of REM sleep. This graph shows the mean \pm SEM duration of REM sleep epochs after mPRF microinjection ( $y$-axis) versus the mean \pm SEM number of REM sleep epochs which occurred in the 2 hr period after mPRF microinjection ( $x$-axis). The mPRF microinjection conditions are indicated by the following symbols: $\mathbf{\square}$, saline; $\boldsymbol{\bullet}, 22.8 \mathrm{mM}$ NLA; $\mathbf{\Delta}, 22.8 \mathrm{~mm}$ NDA; $\square, 40 \mathrm{~mm}$ Neo; $0,22.8 \mathrm{~mm}$ NLA/40 mм Neo; $\triangle$, $22.8 \mathrm{~mm}$ NDA/40 mM Neo. Notice that mPRF NLA administration reduced the duration of REM sleep epochs both for naturally occurring REM sleep (solid symbols) and for the REM sleep-like state (open symbols). The number of REM sleep epochs that occurred both naturally and after Neo injection, however, was not altered by NLA injection. These data suggest that there was an NLA-specific effect on the ability to maintain REM sleep episodes but no effect on the ability to generate REM epochs.

cholinergic neurons and hence participate in REM sleep regulation. Anatomical evidence has shown that NOS is present in the axon terminals and the cell bodies of LDT/PPT cholinergic neurons (Vincent et al., 1983; Mizukawa et al., 1989; Bickford et al., 1993). In addition to decreasing ACh release in the mPRF, NOS inhibition decreased ACh release in the cholinergic PPT cell body region (Fig. 3). The ability of NO production to modulate ACh release in the PPT nuclei suggests that levels of NO, by altering ACh release, may influence the activity of cholinergic neurons known to be important in the generation of REM sleep.

\section{NOS inhibition and anesthesia induced alterations in arousal}

The present study also used halothane anesthesia as an additional tool for examining the relationship between levels of arousal and NOS modulation of ACh release in the mPRF. The results indicate that halothane anesthesia, like PPT NOS inhibition, reduced ACh release in the cholinergic PPT cell body region (Fig. 3). The finding that both PPT NOS inhibition and halothane anesthesia diminished ACh release in the PPT is consistent with results showing that halothane anesthesia significantly reduces $\mathrm{mPRF}$ ACh release (Keifer et al., 1994). Volatile anesthetics, including halothane, have been shown to inhibit NOS in rat cerebellum (Tobin et al., 1994). In addition, halothane has been shown to interfere with the stability of NO (Rengsamy et al., 1995) and the ability of NO to cause vasodilation (Blaise et al., 1994). The idea that NO contributes to the regulation of arousal states also has been supported by data showing that in mice and rats, inhibition of NOS augmented anesthesia, analgesia, and sedation caused by isoflurane and halothane anesthesia (Johns et al., 1992; Ichinose 


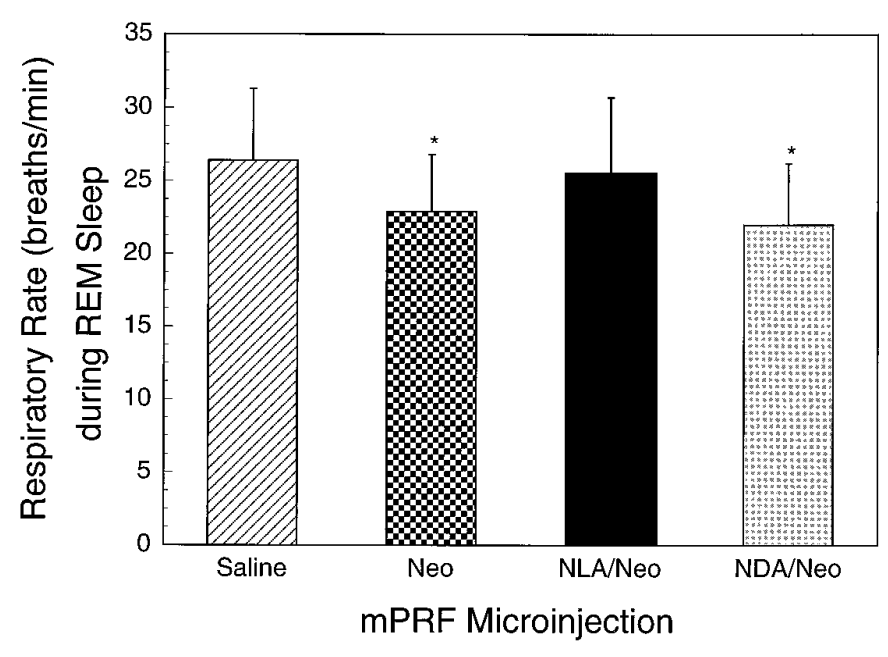

Figure 9. Injection of the NOS inhibitor NLA into the mPRF blocked the cholinergically induced, state-dependent decrease in respiratory rate. Mean + SD respiratory rate (breaths/min) is shown on the ordinate for each of four different mPRF microinjection conditions (abscissa): saline; neostigmine (Neo); NLA/Neo; and NDA/Neo. Compared with saline control, REM sleep respiratory rate was significantly reduced by $\mathrm{mPRF}$ injection of neostigmine $\left({ }^{*} p<0.01\right)$. Injection of NLA before neostigmine $(N L A / N e o)$ prevented the neostigmine-induced decrease in respiratory rate. NDA pretreatment had no significant effect on the cholinergically induced decrease in respiratory rate.

et al., 1995). The finding that NOS inhibition decreased ACh release in the mPRF (Fig. 2) and PPT (Fig. 3) is consistent with reports that both pontine cholinergic stimulation (Keifer et al., 1996) and brain NO (Nistico et al., 1994) contribute to generation of electrocortical (EEG) arousal. The present results (Fig. 3) demonstrating that both NOS inhibition and halothane anesthesia decreased ACh release in the PPT, therefore, are consistent with the notion that $\mathrm{NO}$ and volatile anesthetics may have antagonistic effects on cholinergic modulation of EEG and behavioral arousal.

\section{mPRF NOS inhibition interfered with the maintenance of REM sleep}

Injection of NLA into the mPRF caused a reduction in the time spent in natural REM sleep and attenuated the ability of mPRF neostigmine injection to produce the REM sleep-like state illustrated by Figure 4. More specifically, mPRF NOS inhibition diminished the duration of individual REM sleep epochs but did not alter the latency to REM sleep onset or the frequency of REM sleep episodes (Figs. 5-8). These data suggest that NO production in the mPRF is important for maintaining REM sleep once it has been initiated. NLA in the mPRF inhibited both naturally occurring REM sleep (Fig. 6A) and the cholinergically induced REM sleep state (Fig. 7A). Furthermore, NLA administration decreased the epoch duration of both natural REM sleep and neostigmine-induced REM sleep (Fig. 8).

The similarity between the effects of NOS inhibition on natural REM sleep and the cholinergically induced REM sleep state supports two conclusions. First, these data suggest that mPRF NO production participates in natural REM sleep regulation by modulating pontine cholinergic neurotransmission. Second, these data lend additional support to the premise that endogenous cholinergic neurotransmission plays a major role in natural REM sleep generation. McCarley et al. (1995) noted that REM sleep generation requires the coordinated activation of pools of cholinergic LDT/PPT and noncholinergic, cholinoceptive mPRF neurons.
The present data suggest the possibility that NO may contribute to the recruitment of both cholinergic and cholinoceptive neurons (Fig. 10).

The absence of a significant difference in ACh levels recovered from the mPRF during wakefulness compared with NREM sleep is consistent with previous microdialysis studies of mPRF (Lydic et al., 1991, 1993; Lydic and Baghdoyan, 1993). Wakefulness is the most heterogeneous of behavioral states, and ACh release in the $\mathrm{mPRF}$ also may vary during specific waking behaviors. To the best of our knowledge, all currently available data on pontine ACh release in cat has been obtained from head-restrained animals. Measures of ACh release from the pons of freely moving dog, however, note that motor activity did not significantly alter ACh levels (Reid et al., 1994).

It is interesting to note that microdialysis of large areas of rat thalamus revealed increased ACh release during wakefulness and REM sleep, compared with NREM sleep (Williams et al., 1994). This suggests the possibility that cholinergic LDT/PPT neurons, which selectively increase their discharge rates during REM sleep, project to the mPRF, whereas LDT/PPT neurons with discharge rates that are highest in waking and REM sleep project to various thalamic nuclei (Steriade et al., 1990). Cholinergic LDT/PPT neurons have been noted to be good candidates for disrupting the synchronized spindle oscillations in thalamocortical systems during both arousal and REM sleep (Steriade et al., 1990). Recently, it has been shown that mPRF microinjection of the cholinergic agonist carbachol significantly decreased cortical EEG spindles that normally accompany halothane anesthesia (Keifer et al., 1996).

\section{mPRF NOS inhibition blocked cholinergically mediated respiratory rate depression}

Microinjection of neostigmine into the mPRF is known to produce a REM sleep-like state (Baghdoyan et al., 1984). Presumably, the REM-Neo state results from the accumulation of endogenously released ACh. This assumption is supported by recent evidence showing that mPRF microinjection of vesamicol-like compounds that inhibit vesicular packaging of ACh inhibit REMNeo (Lydic et al., 1996). The present study is the first to show that REM-Neo also is characterized by respiratory rate depression (Fig. 9). The data also show that NLA administration into the mPRF prevented the neostigmine-induced depression in respiratory rate. These data suggest that a reduction in NO production, caused by NLA, resulted in diminished ACh levels within the mPRF and eliminated the neostigmine-induced reduction in respiratory rate. This conclusion is supported by previous studies indicating that pontine cholinergic neurotransmission contributes to respiratory rate depression during the REM sleep-like state caused by mPRF administration of cholinomimetics (Lydic and Baghdoyan, 1992). Both neuroanatomical (Lee et al., 1995) and electrophysiological (Gilbert and Lydic, 1994) data demonstrate pathways whereby the mPRF may influence respiratory rate. The specific mechanisms through which NO, ACh, and mPRF neurons alter breathing remain unknown, but state-dependent respiratory modulation has been shown to involve pertussis toxin-sensitive G-proteins and adenylate cyclase (Shuman et al., 1995) and cAMP signal transduction systems (Capece et al., 1995, 1996).

\section{Limitations and conclusions}

In the present study, the inferences regarding the role of $\mathrm{NO}$ in modulating $\mathrm{ACh}$ release, REM sleep, and respiratory rate are based on the effects of NLA and NDA administration. NOS 


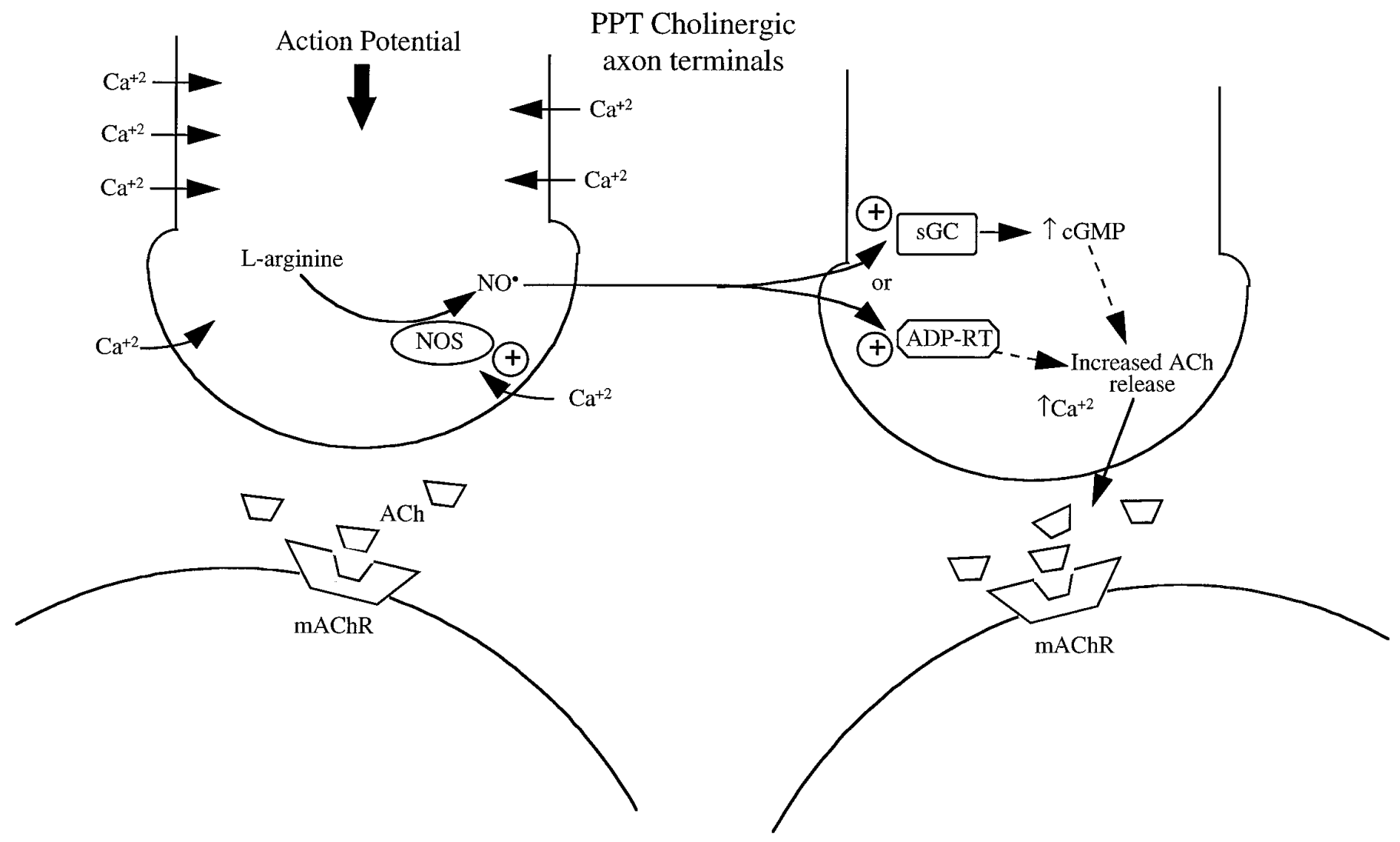

cholinoceptive mPRF neuron

cholinoceptive mPRF neuron

Figure 10. Possible mechanism by which NOS enhances ACh release in regions of the mPRF. Previous studies have presented anatomical (Shiromani et al., 1988) and functional (Lydic and Baghdoyan, 1993) data demonstrating that cholinergic terminals from LDT/PPT neurons regulate ACh release in the mPRF. Normally, the propagation of an action potential into an LDT/PPT neuron terminal would cause an influx of calcium $\left(\mathrm{Ca}^{+2}\right)$, which stimulates NOS known to be present in PPT axon terminals (Vincent et al., 1983; Mizukawa et al., 1989; Bickford et al., 1993). Increased production of $\mathrm{NO}(N O \cdot)$ stimulates target proteins such as soluble guanyl cyclase $(s G C)$ or ADP-ribosyltransferase $(A D P-R T)$. Activation of these proteins would lead to increased ACh release thereby stimulating muscarinic cholinergic receptors on postsynaptic mPRF neurons (Baghdoyan et al., 1994). Each terminal contains all the molecules schematized in the left and right terminals, and inhibition of NOS by NLA in these cells would decrease ACh release (Fig. 2), REM sleep (Fig. 6), and state-dependent changes in respiratory rate (Fig. 9).

inhibitors currently represent one of the most widely used research tools for investigating the role of NO in biological systems (Griffith and Stuehr, 1995). It is acknowledged that the conclusions drawn from the results of these experiments would be strengthened by the use of NO-generating compounds and the in situ electrochemical measurement of NO. The use of NO scavengers such as hemoglobin recently have been shown to provide a technically difficult but promising technique for measuring levels of NO (Williams et al., 1995). Additional studies measuring ACh release in the LDT/PPT during REM sleep also are needed. Such studies are technically difficult, and stereotaxic access to the LDT/PPT in the cat is limited by the presence of an ossified tentorium. Nonetheless, the data shown in Figure 3 represent the first measurements of ACh release in the pontine cholinergic cell body region in the awake and anesthetized cat.

Data presented here provide evidence for the role of NO in facilitating pontine ACh release, maintaining REM sleep once it has been initiated, and participating in the cholinergic modulation of respiratory rate. It is likely that NO influences REM sleep and breathing during REM sleep via modulation of ACh release. NO also may serve to potentiate and prolong the duration of $\mathrm{ACh}$ release from presynaptic axon terminals within the mPRF. The production of NO within the mPRF may be clinically relevant in the cholinergic modulation of statedependent respiratory depression (Pack, 1995), narcolepsy (Reid et al., 1994; Nishino et al., 1995), and REM behavior disorder (Mahowald and Schenck, 1992).

\section{REFERENCES}

Baghdoyan HA, Monaco AP, Rodrigo-Angulo ML, Assens F, McCarley RW, Hobson JA (1984) Microinjection of neostigmine into the pontine reticular formation of cats enhances desynchronized sleep signs. J Pharmacol Exp Ther 231:173-180.

Baghdoyan HA, Lydic R, Callaway CW, Hobson JA (1989) The carbachol-induced enhancement of desynchronized sleep signs is dosedependent and antagonized by centrally administered atropine. Neuropsychopharmacology 2:67-79.

Baghdoyan HA, Spotts JL, Snyder SG (1993) Simultaneous pontine and basal forebrain microinjections of carbachol suppress REM sleep. J Neurosci 13:229-242.

Baghdoyan HA, Mallios VJ, Duckrow RB, Mash DC (1994) Localization of muscarinic receptor subtypes in brain stem areas regulating sleep. NeuroReport 5:1631-1634.

Berman AL (1968) The brainstem of the cat. Madison, WI: University of Wisconsin. 
Bickford ME, Gunluk AE, Guido W, Sherman SM (1993) Evidence that cholinergic axons from the parabrachial region of the brainstem are the exclusive source of nitric oxide in the lateral geniculate nucleus of the cat. J Comp Neurol 334:410-430.

Blaise G, Quy T, Parent M, Lagarde B, Asenjo F, Sauve R (1994) Does halothane interfere with the release, action, or stability of endotheliumderived relaxing factor/nitric oxide? Anesthesiology 80:417-426.

Bredt DS, Glatt CE, Hwang PM, Fotuhi M, Dawson TM, Snyder SH (1991) Nitric oxide synthase protein and mRNA are discretely localized in neuronal populations of the mammalian CNS together with NADPH diaphorase. Neuron 7:615-624.

Capece ML, Fleegal MA, Baghdoyan HA, Lydic R (1995) Transmembrane signal transduction systems mediating cholinergic REM sleep generation. Soc Neurosci Abstr 21:2068.

Capece ML, Fleegal MA, Lydic R (1996) Cyclic AMP and protein kinase $A$ in the pontine reticular formation contribute to cholinergic rapid eye movement (REM) sleep generation. Soc Neurosci Abstr 22:374.

Dawson TM, Bredt DS, Fotuhi M, Hwang PM, Snyder SH (1991) Nitric oxide synthase and neuronal NADPH diaphorase are identical in brain and peripheral tissues. Proc Natl Acad Sci USA 88:7797-7801.

El Mansari M, Sakai K, Jouvet M (1990) Responses of presumed cholinergic mesopontine tegmental neurons to carbachol microinjections in freely moving cats. Exp Brain Res 83:115-123.

Fukuto JM, Chaudhuri G (1995) Inhibition of constitutive and inducible nitric oxide synthase: potential selective inhibition. Annu Rev Pharmacol Toxicol 35:165-94.

Garthwaite J, Boulton CL (1995) Nitric oxide signaling in the central nervous system. Annu Rev Physiol 57:683-706.

Gilbert KA, Lydic R (1994) Pontine cholinergic reticular mechanisms cause state-dependent changes in the discharge of parabrachial neurons. Am J Physiol 266:R136-R150.

Griffith OW, Stuehr DJ (1995) Nitric oxide synthases: properties and catalytic mechanism. Annu Rev Physiol 57:707-736.

Guevara-Guzman R, Emson PC, Kedrick KM (1994) Modulation of in vivo striatal transmitter release by nitric oxide and cyclic GMP. J Neurochem 62:807-810.

Hope BT, Michael GJ, Knigge KM, Vincent SR (1991) Neuronal NADPH diaphorase is a nitric oxide synthase. Proc Natl Acad Sci USA 88:2811-2814.

Iadecola C (1992) Nitric oxide participates in the cerebrovasodilation elicited from cerebellar fastigial nucleus. Am $\mathbf{J}$ Physiol 263: R1156-R1161.

Ichinose F, Huang PL, Zapol WM (1995) Effects of targeted neuronal nitric oxide synthase gene disruption and $G$-nitro-L-arginine methylester on the threshold for isoflurane anesthesia. Anesthesiology 83:101-108.

Johns RA, Moscicki JC, DiFazio CA (1992) Nitric oxide synthase inhibitor dose-dependently and reversibly reduces the threshold for halothane anesthesia. Anesthesiology 77:779-784.

Jones BE (1993) The organization of central cholinergic systems and their functional importance in sleep-waking states. Prog Brain Res 98:61-71.

Kapas L, Fang J, Krueger JM (1994a) Inhibition of nitric oxide synthesis inhibits rat sleep. Brain Res 664:189-196.

Kapas L, Shibita M, Kimura M, Krueger JM (1994b) Inhibition of nitric oxide synthesis suppresses sleep in rabbits. Am J Physiol 266:R151-R157.

Kayama Y, Ohta M, Jodo E (1992) Firing of "possibly" cholinergic neurons in the rat laterodorsal tegmental nucleus during sleep and wakefulness. Brain Res 569:210-220.

Keifer JC, Baghdoyan HA, Becker L, Lydic R (1994) Halothane decreases pontine acetylcholine release and increases EEG spindles. NeuroReport 5:577-580.

Keifer JC, Baghdoyan HA, Lydic R (1996) Pontine cholinergic mechanisms modulate the cortical electroencephalographic spindles of halothane anesthesia. Anesthesiology 84:945-954.

Khalil Z, Helme RD (1992) The quantitative contribution of nitric oxide and sensory nerves to bradykinin-induced inflammation in rat skin microvasculature. Brain Res 589:102-108.

Khanna JM, Morato GS, Shah G, Chau A, Kalant H (1993) Inhibition of nitric oxide synthesis impairs rapid tolerance to ethanol. Brain Res Bull 32:43-47.

Lee LH, Friedman DB, Lydic R (1995) Respiratory nuclei share synaptic connectivity with pontine reticular regions regulating REM sleep. Am J Physiol 268:L251-L262.

Leonard CS, Llinas R (1994) Serotonergic and cholinergic inhibition of mesopontine cholinergic neurons controlling REM sleep: an in vitro electrophysiological study. Neuroscience 59:309-330.

Leonard TO, Lydic R (1995) Nitric oxide synthase inhibition decreases pontine acetylcholine release. NeuroReport 6:1525-1529.

Liu XR, Gillespie JS, Gibson IF, Martin W (1991) Effects of NGsubstituted analogues of L-arginine on NANC relaxation of the rat anococcygeus and bovine retractor penis muscles and the bovine penile artery. Br J Pharmacol 104:53-58.

Luebke JI, Greene RW, Semba K, Kamondi A, McCarley RW, Reiner PB (1992) Serotonin hyperpolarizes cholinergic low-threshold burst neurons in the rat laterodorsal tegmental nucleus in vitro. Proc Natl Acad Sci USA 89:743-747.

Luebke JI, McCarley RW, Greene RW (1993) Inhibitory action of muscarinic agonists on neurons in the rat laterodorsal tegmental nucleus in vitro. J Neurophysiol 70:2128-2135.

Lydic R, Baghdoyan HA (1989) Cholinoceptive pontine reticular mechanisms cause state-dependent respiratory changes in the cat. Neurosci Lett 102:211-216.

Lydic R, Baghdoyan HA (1992) Cholinergic pontine mechanisms causing state-dependent respiratory depression. News Physiol Sci 7:220-224.

Lydic R, Baghdoyan HA (1993) Pedunculopontine stimulation alters respiration and increases ACh release in the pontine reticular formation. Am Physiol 264:R544-R554.

Lydic R, Baghdoyan HA (1994) The neurobiology of rapid-eyemovement sleep. In: Sleep and breathing (Saunders NA, Sullivan CE, eds), pp 47-77. New York: Marcel Dekker.

Lydic R, Baghdoyan HA, Zwillich CW (1989) State-dependent hypotonia in posterior cricoarytenoid muscles of the larynx caused by cholinoceptive reticular mechanisms. FASEB J 3:1625-1631.

Lydic R, Baghdoyan HA, Lorinc Z (1991) Microdialysis of cat pons reveals enhanced acetylcholine release during state-dependent respiratory depression. Am J Physiol 261:R766-R770.

Lydic R, Keifer JC, Baghdoyan HA, Becker L (1993) Microdialysis of the pontine reticular formation reveals inhibition of acetylcholine release by morphine. Anesthesiology 79:1003-1012.

Lydic R, Capece ML, Efange SMN (1996) Pontine microinjection of 4-aminobenzovesamicol (ABV) blocks cholinergic rapid eye movement (REM) sleep. Soc Neurosci Abstr 22:1030.

Mahowald MW, Schenck CH (1992) Dissociated states of wakefulness and sleep. Neurology 42:44-52.

McCarley RW, Greene RW, Rainnie D, Portas CM (1995) Brainstem neuromodulation and REM sleep. Semin Neurosci 7:341-351.

Mitani A, Ito K, Hallanger AE, Wainer BH, Kataoka K, McCarley RW (1988) Cholinergic projections from the laterodorsal and pedunculopontine tegmental nuclei to the pontine gigantocellular tegmental field in the cat. Brain Res 451:397-402.

Mizukawa K, Vincent SR, McGeer PL, McGeer EG (1989) Distribution of reduced-nicotinamide-adenine-dinucleotide-phosphate diaphorasepositive cells and fibers in the cat central nervous system. J Comp Neurol 279:281-311.

Nishino S, Tafti M, Reid MS, Shelton J, Siegel JM, Dement WC, Mignot E (1995) Muscle atonia is triggered by cholinergic stimulation of the basal forebrain: implications for the pathophysiology of canine narcolepsy. J Neurosci 15:4806-4814.

Nistico G, Bagetta G, Iannone M, Del Duca C (1994) Evidence that nitric oxide is involved in the control of electrocortical arousal. In: The neurobiology of NO and OH (Chiueh CC, Gilbert DL, Colton CA, eds), pp 191-200. New York: New York Academy of Sciences.

Ohkuma S, Kuriyama K (1994) Roles of nitric oxide in neurotransmitter release: analysis using primary cultured CNS neurons. In: Nitric oxide: roles in neuronal communication and neurotoxicity (Takagi H, Toda N, Hawkins RD, eds), pp 171-180. Tokyo: Japan Scientific Societies.

Ohkuma S, Katsura M, Chen D-Z, Narihara H, Kuriyama K (1995) Facilitation of $N$-methyl-D-aspartate-evoked acetylcholine release by hydroxyl radical scavengers. NeuroReport 6:2033-2036.

Pack AI (1995) Changes in respiratory motor activity during rapid eye movement sleep. In: Regulation of breathing, 2nd Ed (Dempsey JA, Pack AI, eds), pp 983-1010. New York: Marcel Dekker.

Prast H, Philippu A (1992) Nitric oxide releases acetylcholine in the basal forebrain. Eur J Pharmacol 216:139-140.

Prast H, Fischer H, Werner E, Werner-Felmayer G, Philippu A (1995) Nitric oxide modulates the release of acetylcholine in the ventral striatum of the freely moving rat. Naunyn Schmiedebergs Arch Pharmacol 352:67-73.

Reid MS, Siegel JM, Dement WC, Mignot E (1994) Cholinergic mech- 
anisms in canine narcolepsy-II. Acetylcholine release in the pontine reticular formation is enhanced during cataplexy. Neuroscience 59:523-530.

Rengsamy A, Ravichandran LV, Reikerdorfer CG, Johns RA (1995) Inhalational anesthetics do not alter nitric oxide synthase activity. J Pharmacol Exp Ther 273:599-604.

Semba K, Fibiger HC (1992) Afferent connections of the laterodorsal and pedunculopontine tegmental nuclei in the rat: a retro- and anterograde transport and immunohistochemical study. J Comp Neurol 323:387-410.

Shiromani PJ, Armstrong DM, Gillin JC (1988) Cholinergic neurons from the dorsolateral pons project to the medial pons: a WGA-HRP and choline acetyltransferase immunohistochemical study. Neurosci Lett 95:19-23.

Shouse MN, Siegel JM (1992) Pontine regulation of REM sleep components in cats: integrity of the pedunculopontine tegmentum (PPT) is important for the phasic events but not necessary for atonia during REM sleep. Brain Res 571:50-63.

Shuman SL, Capece ML, Baghdoyan HA, Lydic R (1995) Pertussis toxinsensitive $G$ proteins mediate carbachol-induced REM sleep and respiratory depression. Am J Physiol 269:R308-R317.

Steininger TL, Rye DB, Wainer BH (1992) Afferent projections to the cholinergic pedunculopontine tegmental nucleus and adjacent midbrain extrapyramidal area in the albino rat. I. Retrograde tracing studies. J Comp Neurol 321:515-543.

Steriade M, McCarley RW (1990) Brainstem control of wakefulness and sleep. New York: Plenum.

Steriade M, Datta S, Pare D, Oakson G, Curro Dossi R (1990) Neuronal activities in brainstem cholinergic nuclei related to tonic activation processes in thalamocortical systems. J Neurosci 10:2541-2559.

Tanaka M, Yoshida S, Yano M, Hanaoka F (1994) Roles of endogenous nitric oxide in cerebellar cortical development in slice cultures. NeuroReport 5:2049-2052.

Tobin JR, Martin LD, Breslow MJ, Traystman RJ (1994) Selective anesthetic inhibition of brain nitric oxide synthase. Anesthesiology 81:1264-1269.

Ursin R, Sterman MB (1981) A manual for standardized scoring of sleep and waking states in the adult cat. Los Angeles: Brain Information Service/Brain Research Institute, University of California.
Vanni-Mercier G, Sakai K, Lin JS, Jouvet M (1989) Mapping of cholinoceptive brainstem structures responsible for the generation of paradoxical sleep in the cat. Arch Ital Biol 127:133-164.

Vincent SR, Satoh K, Armstrong DM, Fibiger HC (1983) NADPHdiaphorase: a selective histochemical marker for the cholinergic neurons of the pontine reticular formation. Neurosci Lett 43:31-36.

Wang Q, Pelligrino DA, Koenig HM, Albrecht RF (1994a) The role of endothelium and nitric oxide in rat pial arteriolar dilatory responses to $\mathrm{CO}_{2}$ in vivo. J Cereb Blood Flow Metab 14:944-951.

Wang Q, Theard MA, Pelligrino DA, Baughman VL, Hoffman WE, Albrecht RF, Cwik M, Paulson OB, Lassen NA (1994b) Nitric oxide (NO) is an endogenous anticonvulsant but not a mediator of the increase in cerebral blood flow accompanying bicuculline-induced seizures in rats. Brain Res 658:192-198.

Wang Y-X, Zhou T, Pang CC (1991) Pressor effects of L and D enantiomers of NG-nitro-arginine in conscious rats are antagonized by L- but not D-arginine. Eur J Pharmacol 200:77-81.

Wang Y-X, Poon CI, Pang CCY (1993) In vitro and ex vivo inhibitory effects of L- and D-enantiomers of Ng-nitro-arginine on endotheliumdependent relaxation of rat aorta. J Pharmacol Exp Ther 265:112-119.

Webster HH, Jones BE (1988) Neurotoxic lesions of the dorsolateral pontomesencephalic tegmentum-cholinergic area in the cat. II. Effects upon sleep-waking states. Brain Res 458:285-302.

Williams JA, Reiner PB (1993) Noradrenaline hyperpolarizes identified rat mesopontine cholinergic neurons in vitro. J Neurosci 13:3878-3883.

Williams JA, Comisarow J, Day J, Fibiger HC, Reiner PB (1994) Statedependent release of acetylcholine in rat thalamus measured by in vivo microdialysis. J Neurosci 14:5236-5242.

Williams JA, Vincent SR, Reiner PB (1995) State-dependent production of nitric oxide in rat thalamus as measured by in vivo microdialysis. Sleep Res 24A:70.

Yamamoto K, Mamelak AN, Quattrochi JJ, Hobson JA (1990) A cholinoceptive desynchronized sleep induction zone in the anterodorsal pontine tegmentum: spontaneous and drug-induced neuronal activity. Neuroscience 39:295-304.

Zhang J, Benveniste H, Klitzman B, Piantadosi CA (1995) Nitric oxide synthase inhibition and extracellular glutamate concentration after cerebral ischemia/reperfusion. Stroke 26:298-304. 